\title{
The waiting game: A primary care intervention to improve access to specialist care to patients with osteoarthritis
}

\author{
Laura Katherine Churchill
}

\section{University of Western Ontario}

Osteoarthritis (OA) commonly presents in the major weight bearing joints such as the knee and contributes to debilitating pain as well as impairments of physical function. As of 2011, one in eight Canadians (13\%) suffer from this condition. ${ }^{1}$ Given appropriate candidacy, surgical treatment for end-stage knee OA such as total knee replacement (TKR) and high tibial osteotomy (HTO) are highly successful with negligible risk. ${ }^{2}$ Just as the population has aged over the past decade, so too has the demand for surgical treatment of OA increasing wait times across Canada. ${ }^{3-6}$ The 2012 Wait Time Alliance report found that the wait times for an initial surgical consult are as problematic as the wait times for the surgeries themselves. ${ }^{6}$

Cipriano et al. (2008) 7 identified that wait times for TKR in Ontario are longer than clinically appropriate. The current federal benchmark for TKR is no longer than 6 months for low priority patients, while high and intermediate priority patients should undergo surgery 1 and 3 months respectively from the time the decision for surgery is made. Using information from the Ontario joint replacement registry (OJRR), Cipriano et al. (2008) ${ }^{7}$ conducted a simulation study that suggests that Ontario would need to increase the number of available procedures by $12 \%$ annually over 10 years to ensure that $90 \%$ of patients underwent TKA within 6 months. $^{7}$

McHugh et al. (2011) ${ }^{8}$ found that patient referrals to a surgeon by general practitioners are often inappropriate, reporting that only $33 \%$ of patients actually underwent surgery. Of those patients who did not, the majority were referred back to their general practitioner because they either did not wish to undergo a surgical intervention, had not yet exhausted non-surgical options (physiotherapy, injections, weight loss), had been referred to the wrong type of specialist (i.e. arthroscopy), or were not in a condition severe enough to warrant a TKR. ${ }^{8}$

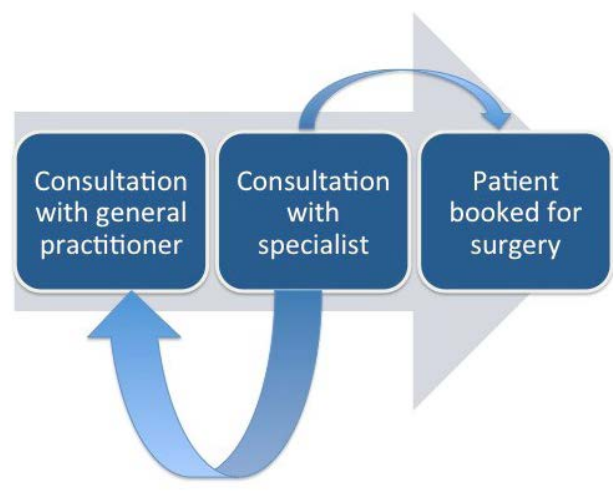

Figure 1- Large proportion of inappropriate referrals to specialists

A study by Klett et al. $(2012)^{9}$ implemented an intermediate surgical screening clinic and found that of the 327 patients assessed, 155 (47.4\%) were referred back to their general practitioner (Figure 1). The authors suggested that strategies emphasizing appropriate referral may improve access to TKR. ${ }^{9}$

Strategies to improve the quality of referrals to surgery will reduce wait time to first consultation with a surgeon.

The current practice guidelines suggest: physiotherapy, strengthening exercise, weight loss, walking aids, injections, and anti-inflammatories as frontline treatments for patients with knee OA prior to joint replacement. In a Canadian study conducted by DeHann et al. $(2007)^{10}$ the authors evaluated the congruence between a physician training rheumatology-teaching clinic and current evidence-based guidelines for patients with knee OA. Of the 105 randomly selected patients the most commonly recommended non-pharmacologic treatment included: exercise (58.1\%), physiotherapy (42.9\%), and strengthening exercise (40.0\%). Moreover, education, aerobic and 
range of motion exercise, social support, orthoses, assistive devices for ambulation, acupuncture, and occupational therapy/energy conservation were documented in under $30 \%$ of patient charts, implying the underutilization of conservative strategies in managing knee OA. These results suggest that better strategies to educate and encourage physician adherence to current $\mathrm{OA}$ recommendations are still needed. ${ }^{10}$

It is possible that the referring physician feels it is the role of the orthopaedic surgeon to present patients with the resources, options, and recommendations regarding surgery. The greatest improvement in efficiency may begin with improving education, such that the primary physician can feel more confident in determining the severity of knee $\mathrm{OA}$, managing a non-surgical treatment plan, and introducing preliminary discussions of surgical options with their patients.

Providing a means to reduce inappropriate referrals and better informing the decision to refer to surgery for knee $\mathrm{OA}$ could potentially reduce wait times that currently hinder our health care system. Thus, strategies that provide a greater awareness of the guidelines for treatment of knee $\mathrm{OA}$, greater accountability by general practitioners for nonsurgical options, and effective diagnostic decision-making support are needed.

\section{References}

1. Arthritis Alliance of Canada. The impact of arthritis in canada: Today and over the next 30 years [Internet]. 2011. Accessed December, 2012. Available from: http://www.arthritisnetwork.ca/downloads/ 20111022 Impact_of_arthritis.pdf. Updated 2011.

2. Dennis MG, Di Cesare PE. Surgical management of the middle age arthritic knee. Bull Hosp Jt Dis. 2003;61(3-4):172.

3. Canadian Institute for Health Information, Canadian Joint Replacement Registry. Hip and knee replacements in canada. Hip and knee replacements in Canada. 2008.

4. Kurtz SM, Walter WL, de Steiger R, et al. International survey of primary and revision total knee replacement. Int Orthop. 2011;35(12):1783-1789.

5. Blackstein-Hirsch, P., Gollish, J., Hawker, G., Kreder, H., Mahomed,N., Williams, J. Information strategy: Urgency rating, waiting list management and patient outcomes monitoring for primary hip/knee joint replacement. 2000:00-04

6. Wait Time Alliance. Shedding light on canadians' total wait for care [Internet]. Accessed December, 2012. [cited 2014 Feb 6] Available from: http://www.waittimealliance.ca/media/2012reportcard/WTA2012reportcard_e.pdf. 2012.

7. Cipriano LE, Chesworth BM, Anderson CK, Zaric GS. An evaluation of strategies to reduce waiting times for total joint replacement in ontario. Med Care. 2008:46(11):1177-1183.

8. McHugh GA, Campbell M, Luker KA. GP referral of patients with osteoarthritis for consideration of total joint replacement: A longitudinal study. The British journal of general practice : the journal of the Royal College of General Practitioners. 2011;61(589):459-501.

9. Klett M, Frankovich R, Dervin GF, Stacey D. Impact of a surgical screening clinic for patients with knee osteoarthritis: A descriptive study. Clin J Sport Med .2012;22(3):274-277.

10. DeHaan MN, Guzman J, Bayley MT, Bell MJ. Knee osteoarthritis clinical practice guidelines: How are we doing? J Rheumatol. 2007;34(10):2099-2105.

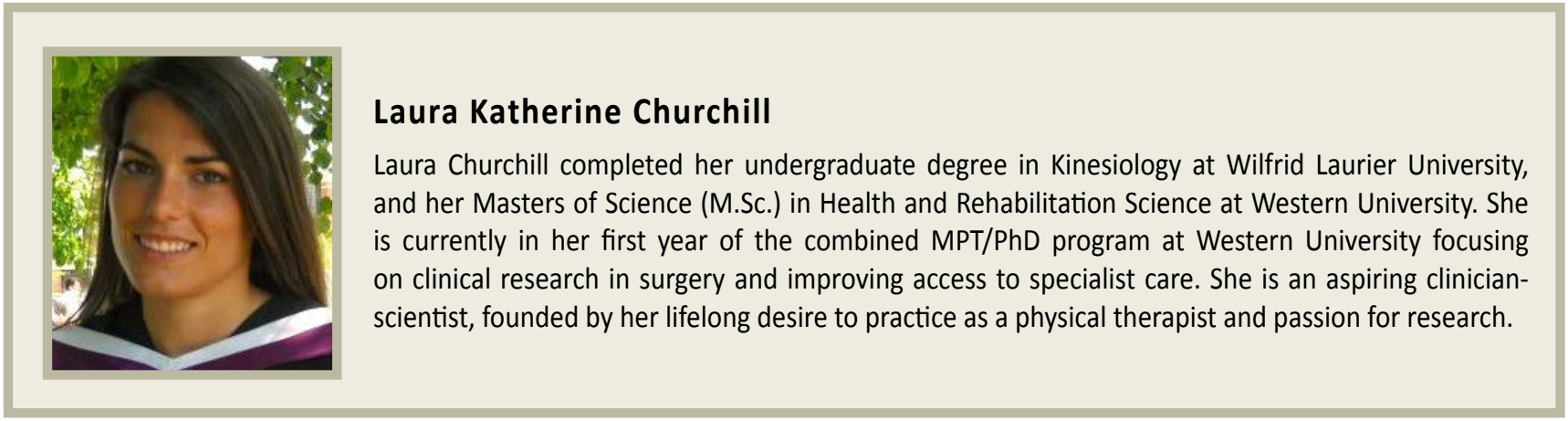

